\title{
The Impact of Collaborative Writing and The Stream of Consciousness Technique on Writing
}

\author{
Çelen Dimililer ${ }^{*}$, Mustafa Kurt ${ }^{2}$ \\ ${ }_{1,2}$ Near East University, Nicosia, Northern Cyprus \\ *Corresponding author: celen.dimililer@ neu.edu.tr
}

\begin{abstract}
This experimental research study attempted to examine the effectiveness of an advanced writing course integrating the stream of consciousness technique and collaborative writing. The writing course was designed for eleven undergraduate English as foreign language students studying at the English language teaching department. Adopting a mixed methods research design, qualitative and quantitative data were used to answer the research questions. Qualitative data were gathered from pre and post-intervention interviews and the quantitative data from the pre and post-tests. The results revealed that a great majority of the participants made considerable progress in terms of creativity and overall writing performance. The fact that the intervention was effective was apparent in a great majority of the participants' preference for collaborative writing over individual writing and all participants' preference for the stream of consciousness technique over traditional writing modes. In terms of the use of the stream of consciousness technique and collaborative writing, it was found that collaborative writing was a more pleasing experience. It was also found that due to the intervention they not only made good progress in terms of their writing skills but also their attitudes changed in a positive way towards writing.
\end{abstract}

Keywords: creativity in writing, collaborative writing, English as a foreign language writing, prospective English teachers, Stream of Consciousness Technique.

\section{Introduction}

Due to the requirement of a combination of many skills inherent in good writing skills, writing is believed to be a challenging task. In order to produce well written texts, students have to learn and practise each of the skills like correct grammar, a good range of vocabulary, accurate spelling, correct punctuation, preparing an outline, planning, finding original ideas, coherence and proofreading very well. Myles (2002) argues that students must be taught writing specifically, otherwise, they cannot master desirable writing skills by themselves. As I observed during my teaching experience, most EFL students studying in North Cyprus whether they are 
preparatory school students or undergraduate students have difficulties in terms of writing.

Pineteh (2013) argues that some problems concerning EFL writing originate from the fact that writing teachers sometimes give inconsistent feedback. The problems originating from students, on the other hand, are due to the lack of analytical skills (Pineteh, 2013). In terms of Turkish EFL students, Solak and Bayar (2015) argue that Turkish students do not get proper writing education, because teachers pay more attention to grammar in EFL classes and all they do is exam-oriented.

Writing is a neglected skill in the Turkish Cypriot as well as the Turkish context. Students studying at the English Language Teaching Department are mostly Turkish Cypriot. A few of these students are native-speakers of English and most of them are EFL learners. The non-native speakers of English studying at this department did not receive proper writing instruction before. During their writing classes these students are expected to learn how to teach writing while their own writing skills are not at a desirable standard. The students who took part in this study had never tried new techniques like collaborative writing or the stream of consciousness technique in their writing classes before.

Traditional ways of teaching writing are mostly outdated and straightforward neglecting students' higher order thinking skills. Besides, students hold back because of such constraints as low proficiency level and the rules of writing, which in turn impair their writing skills. However, if teachers find ways to enhance their students' creativity and imagination through teaching higher order thinking skills, it will foster their writing skills, too (White, 1991). At this point, the stream of consciousness technique may help since it gives students the freedom they would love to have.

In most academic EFL writing classes in North Cyprus, writing is viewed as a solitary task. This study poses that when students study in groups they will get inspired by their peers and this will foster their creativity and imagination which will contribute to their writing skills (Storch, 2005). To recap, this research study suggests that the problems in writing classes in terms of originality can be solved through the stream of consciousness technique as well as collaborative writing.

\section{Aim of the Study}

The main aim of this study was to investigate the effect of incorporating collaborative writing, the stream of consciousness technique and short story writing 
in EFL writing course. More specifically, the following research questions were addressed:

1. What are the students' perspectives on their own writing skills before they are exposed to the stream of consciousness technique and collaborative writing?

a) What are the challenges they experience concerning writing?

2. In what ways do the stream of consciousness technique and collaborative writing affect undergraduate EFL students' creative writing skills and overall writing performances?

3. What are the undergraduate EFL students' perspectives on?

a) the stream of consciousness technique?

b) the collaborative writing?

\section{Theoretical Background}

In this section Collaborative Writing and The Stream of Consciousness Technique are presented.

\section{Collaborative Writing}

Writing was considered as a solitary individual activity in the past (Hedgcock \& Lefkowitz, 1992). Later on, in order to ensure interaction and knowledge coconstruction group activities are incorporated into L2 writing classes (Dobao, 2012). As well as academic writing, in which students are generally asked to work on their own, we believe learners should also be encouraged to work in groups. There is a great deal of literature supporting this view. A very interesting work on this argues for its vital nature in teaching writing (Honigsfeld \& Dove, 2012, p. 231). The argument is that peers interacting and cooperating in the classroom "peer group mentoring" - enhances overall success for any group of learners.

The technique of brainstorming is by no means new, nor is the idea of collaborative/cooperative learning. Jolliffe (2007, p. 6) puts it in seemingly contradictory terms. She writes of "Positive Interdependence - 'We sink or swim together'" and "individual accountability - 'No Hitchhiking.," The first contention 
is that each member of a group of learners should contribute to the learning situation, and that each learner is dependent on the others for this kind of positive outcomes desired. The individual needs the group, and the group needs the individual. The ethos to be cultivated is a sense of we are all in this together. The second contention is that the task of the individual is that individual's responsibility, and that person must complete such work in order to further the interests of the group. One writes "seemingly contradictory" as in fact the dynamic interplay between the individual and the group is at the heart of cooperative learning.

Research shows that collaborative writing improves writing skills. Storch (2005) has investigated the effectiveness of using small groups in improving ESL writing skills by comparing texts written in groups with others written individually in an ESL classroom at an Australian university. The participants are given the opportunity to work either individually or collaboratively. Out of 23 participants, only five participants choose to work individually while the 18 preferred to work collaboratively. The treatment period has lasted four weeks. It is found that the students who have worked collaboratively have spent more time than the students who have written individually. Writing should be integrated into all other aspects of language learning, and not be taught as an isolated activity. Indeed, there can be no isolated aspect to language learning. It is a holistic thing, and teachers ignore this at their peril (Nation, 2009, p. 150).

When the word 'holistic' is used, it is inescapable for a teacher of the English language to address the issue of the cultures of the countries of the language's origin. Abdulrahman (2012) strongly argues that lack of attainment in writing in English among Kurdish learners is held back severely by a lack of "socio-cultural dimensions." He feels that greater exposure to the culture and way of life of nations in which English is the native language could redress this. A non-native speaker teacher can use collaborative writing techniques to induce students to research together the cultures and ways of life concerned, perhaps to the point of outstripping the knowledge of the teacher. Research is at the heart of collaborative writing.

\section{Stream of Consciousness Technique}

In terms of literature and literary criticism, stream of consciousness refers to thoughts and ideas, held in the mind, or passing through the mind, which are not necessarily coherent or logical. James (1890) called this phenomenon an "interior dialogue," in his The Principles of Psychology. Dainton (2000) argues the 
importance of James' assertion with a question which highlights the importance he attaches to it. "What is the basic architecture of consciousness? How are time and space manifest in conscious experience? Is consciousness really like a stream, as James famously argued?" Dainton, James' famous brother, Henry James, foreshadowed these ideas in such novels as The Portrait of a Lady, Princess Cassimassima and Roderick Hudson in which he follows the intimate thoughts of his characters. James in his preface to The Portrait of $a$ Lady, writes of "movement, into a march or a rush, a pattern of quick steps" (p.8) in respect to his main character, Isabel Archer. This echoes the 'stream of thought' of his brother William James's coinage, first appearing in The Principles of Psychology (1890). This stream of thought is a bold attempt to get away from the all too easy parcelling and categorising of thought and ideas, an attempt to see it for what it is free flowing, generally not under control, often random, and often leading to wholly unexpected outcomes.

Freud, on being hailed the founder of psychoanalysis modestly argued that in fact the great novelists had done this, and that he had merely systematised the study. Whether his assertion is true or not is outside the scope of this work, yet we may wish to point out that Freud drew on literature to an enormous extent in his lectures and writings on psychoanalysis (Freud \& Wilson, 2012). The stream of consciousness that Freud found in the great European novels was reflected in his therapeutic techniques, with a free flow of ideas from his patients on his famous couch, word association, and other forms of expression which are liberated from formal control.

It could be argued that the stream of consciousness as a literary device goes back even further. Shakespeare has Hamlet uttering long soliloquies, notably the one beginning "To be, or not to be..." (p.1024) in which he gives the audience a long stream of his private thoughts. Throughout the play he is often incoherent, and he often repeats himself. Here, Shakespeare presents a mind tumbling with ideas and impulses, racing and abruptly stopping. Hamlet mixes his metaphors, comes out with ideas that clash with each other, and issues strange instructions to himself (e.g. to write down somewhere that a man can smile and be a villain). The audience is half convinced that he is mad, but also half convinced that he is the authentic voice of real discourse such as we all practice in stark contrast to the unnaturally structured and still discourse of formal writings by lesser writers.

Joyce (1922) takes the stream of consciousness to far greater levels of disjointed and seemingly incoherent levels in Ulysses. The book is set in Dublin, and the timeframe is one single day, which lends intensity to the inner workings of the characters' minds and this is the essence of the novel. Rather than telling a 
structured story of how things shape up over time, the drama and the moving human saga is very internal. The book was very controversial and was initially banned. Yet it became recognised as one of the greatest novels of the $20^{\text {th }}$ Century. In Molly Bloom's (1922) internal monologue, she reflects thus:
"Let me see if I can doze off 12345 what kind of flowers are those they invented like the stars the wallpaper in Lombard street was much nicer the apron he gave me was like that something only I only wore it twice better lower this lamp...." (p. 130).

Here the lack of punctuation reflects the unpunctuated stream of thought; the mixing of numbers suggests an escape from prose - or the prosaic; and the juxtaposition of stars and wallpaper suggests the absurdity of pure thought as opposed to language ordered and addressed to another for the purpose of ordered communication. Also, "better lower this lamp" (p.130) suggests that Molly recollects herself - again, an internal function of thought. Like Hamlet, she is issuing rambling instructions to herself, as we all do. This is as close as the written word can get to real thought and real production of language in the absence of a formal task, such as a speech to outline plans or persuade others through rhetoric. Joyce rightly believes that such utterances are rare while the human mind races on.

In his Portrait of the Artist as a Young Man, Joyce also explores the themes of the human mind in a state of stream of consciousness. As Belanger (2001, vii) puts:

The formal and narrative innovations of Joyce's later work in particular have led many critics to read his works in terms of an early twentiethcentury movement in Western art and literature that has come to be known as Modernism, and which includes the work of Ezra Pound, Virginia Woolf and T.S. Elliot. Characterised by an experimental and self-reflexive approach to form and language, modernist literature is also thought as antirealist, distinguished by a loss of belief that a stable 'real' world can unproblematically be depicted in representational language.

Here we have the essence of stream of consciousness. We find the need to discover alternative means of expression to the formal and artificially organised.

\section{Method}

In order to be able to answer the research questions adequately, it was decided to adopt a mixed methods research design. Such a design employs both qualitative and quantitative elements. In terms of type, the current research was qual+quan 
(Johnson et al., 2007) which meant that it was qualitative dominant and that a qualitative constructivist approach was deployed. Quantitative data were collected sequentially. With regard to the rationale for mixed methods research, treatment integrity ensured assessing the effectiveness of the intervention. A pre-test-post-test design was used. For this reason, this study is a quasi-experimental study. In this quasi-experimental study as there was not a control group, a pre-experimental design was employed. In one group pre-test-post-test design, there is only one group that is pre-tested before the intervention and post- tested after the treatment (Gay \& Pirasian, 2000). As in all experimental designs, it was aimed to determine whether the intervention had any effect on the participants' writing skills in this one group pre-test -post-test study.

\section{Procedure}

In an attempt to investigate the impact of the stream of consciousness technique on their writing skills, the participants were interviewed first to elicit information about their demographics and writing experience. During the initial interviews, semi-structured questions were posed to understand the participants' perspectives on writing in general and on their writing background. More specifically, the interview questions were designed so as to elicit information about their general views of their own writing skills. Further, they were questioned about the efforts they had made to improve these skills and what kind of problems they had come across concerning written assignments. Then the interview focused on a recent writing assignment, what it was about and what steps they took to make sure they improved this written assignment. Next, they were asked what collaborative writing meant to them. Then we moved on to feedback and discussed what corrective feedback they had got from their lecturers regarding writing skills. We concluded with discussing their feelings and worries about making mistakes while writing.

The data collected through the initial interviews were analysed qualitatively to elicit information about their writing background, the difficulties they came across while writing and their efforts to improve their writing skills and their feelings towards writing in general and more specifically about making mistakes while writing. The post-intervention interviews were carried out right after the treatment period. There were semi-structured questions about how they found the intervention, how the intervention affected their writing skills, their feelings and their concerns while writing their parts in the short stories. Both interviews were semi-structured because as Norton (2009) put since they are more flexible, the 
interviewer can ask for further clarifications where necessary providing deeper insights concerning respondents' perspectives.

The results of the initial interviews before the intervention period were compared with the results of those of the interviews conducted after the intervention period to see the changes in the participants' perspectives towards writing. Thus, the initial interviews along with the post-intervention interviews were analysed to answer the research questions about the undergraduate English Language Teaching (ELT) students' perspectives on the effect of the stream of consciousness technique and collaborative writing on their creative writing skills.

Then, at the initial stage of the intervention, the participants were asked to write a short story individually. These short stories were marked by five external examiners, who were employed at the ELT department, according to the criteria which we developed. After the intervention period, the students were asked to write short stories collaboratively with the Stream of Consciousness technique which were marked by the same five external examiners. The results of the first stories which were considered the pre-test were compared with those of the short stories written after the intervention which were considered the post-test. The Wilcoxon signed ranks test was performed to determine to what extent their writing skills were affected by the intervention which helped to answer the research question about how the stream of consciousness technique help undergraduate ELT students to improve their creative writing skills as well as overall writing performance. Thus, the quantitative data were collected and evaluated in accordance with the pre-test - post-test design.

\section{Context of the study}

This experimental study was conducted in the Turkish Cypriot context with eleven senior English Language Teaching students studying at a private university in North Cyprus in the fall semester of 2016-2017. The English Language Teaching Department offers two writing courses in total during the first year of the course of this program. ELT 153 Reading and Writing I is offered in the fall semester and ELT 154 Reading and Writing II is offered in the spring semester. Students have to take and pass ELT 153 Reading and Writing I to be able to take ELT 154 Reading and Writing II since they are prerequisites. As can be seen from the titles of the courses, these courses are a combination of reading and writing as directed by the Turkish Higher Education Council. In the past reading and writing were offered as separate courses but now the department cannot offer a separate writing course as a compulsory course. For this reason, an advanced writing course was designed to be 
offered as an elective course for senior students for this experimental study. It was designed as a three- credit course. Eleven senior students enrolled to this course.

Since the aim was to develop undergraduate ELT students' writing skills, collaborative writing, the stream of consciousness technique and short story writing were also incorporated into this advanced elective course. Despite the fact that all participants had taken writing courses, they were not familiar with the stream of consciousness technique, collaborative writing or short story writing. That's why, the course involved teaching of the above mentioned techniques as well. The students were informed in advance about the assessment breakdown which was as follows:

Tasks $10 \%$

1st. Short story $30 \%$

2nd. Short story $40 \%$

Participation $20 \%$

As the breakdown suggested, there was not any mid-term or final examination for the course. Rather, the students were assessed based on their writing performances. There was no class during mid-term and final examination weeks. Thus, this course was held for fourteen weeks. As the first week was for the initial interviews, the second for writing short stories individually and the last week for post-intervention interviews, the intervention lasted eleven weeks which were thirty -three hours. Figure 1 below illustrates the design for the advanced writing course incorporating the stream of consciousness, collaborative writing and short story writing.

Individual Short Teaching of the Stream Teaching of

Story Writing $\Rightarrow$ of Consciousness Technique $\Rightarrow$ Collaborative Writing

$\Rightarrow$ Practising Collaborative Short Story Writing

Adopting the Stream of Consciousness Technique

Figure 1. The conceptual framework for advanced writing 


\section{Participants}

The participants of this study consisted of eleven senior English Language Teaching students at a private university in North Cyprus. The details about each participant's demographics were necessary to be displayed because each participant's opinions and beliefs were discussed in relation to their demographics. As shown in Table 1, the age range of the participants was 20 to 37 years. Seven of them were female and four of them were male. All of them had taken the two writing courses offered by the department previously. Two of the female students were born and brought up in England but they were of Turkish Cypriot origin. Four female students and two male students were from Turkey. Two male students were Cypriot and one female student was from Turkmenistan. Except the two British students who were native speakers of English, the remaining nine students were all English as a Foreign language (EFL) learners (see Table 1). All the participants took place in the study with their pseudonyms (see Table 1).

\section{Table 1}

\begin{tabular}{l}
\hline Participants' Demographics \\
\begin{tabular}{|l|l|l|l|l|}
\hline Participant & Nationality & Age & Mother-tongue & Gender \\
\hline Dennis & Turkmenistan & 20 & Turkmen & Female \\
\hline Sally & Turkish & 21 & Turkish & Female \\
\hline Gina & Turkish & 23 & Turkish & Female \\
\hline Tom & Turkish & 22 & Turkish & Male \\
\hline Bradley & $\begin{array}{l}\text { Turkish } \\
\text { Cypriot }\end{array}$ & 25 & Turkish & Male \\
\hline Albert & $\begin{array}{l}\text { Turkish } \\
\text { Cypriot }\end{array}$ & 23 & Turkish & Male \\
\hline Aisha & Turkish & 36 & Turkish & Female \\
\hline Mina & British & 22 & English\&Turkish & Female \\
\hline Jenny & Turkish & 22 & Turkish & Female \\
\hline Ken & Turkish & 21 & Turkish & Male \\
\hline Faith & British & 23 & English\&Turkish & Female \\
\hline
\end{tabular}
\end{tabular}

\section{Data Collection}

The initial textual data were gathered via the interviews which were carried out during the first week before the intervention. During the second week, the participants were engaged in short story writing individually, which would be the pre-test in this research study. During the intervention period, initially the stream of consciousness technique was introduced to the students. To do this, the participants were asked to read about this technique and come to class prepared. Rather than 
my delivery of the definition of the technique, brainstorming sessions were held about this technique. An interactive learning environment was provided by this way.

We also discussed how this technique was applied in Mrs. Dalloway by Virginia Woolf. As a follow up activity each student was asked to write a short paragraph adopting this technique. I was there whenever they needed help monitoring and observing them. During the intervention period, in addition to the stream of consciousness technique, the participants were introduced to the collaborative writing. Collaborative writing was taught adopting the same approach for teaching the stream of consciousness technique. We came up with the definition that collaborative writing meant a joint work to which every participant contributed by reading the previous part or parts and writing his /her own part adding developing or giving a twist so that the next student could have something to elaborate. The students were assured to realize that this was a shared responsibility.

Then, we decided about the way they would be applying collaborative writing. Each student would have a different coloured pen to write his/her part and after reading the previous contribution or contributions he /she would add his / her own part. Having this in mind, students practised writing a short story. A volunteering student started the story, and everyone made their contributions one by one in different coloured pens. It was assumed that the students would try to develop the story logically. For example, if the first part was about the setting of the story, they would contribute to the time and place of the story but if the previous part was about the characters, they would develop the character sketch. At the same time, it was assumed that they would try to be as accurate as possible. The aim of this activity was twofold. One was to enable them to practise collaborative writing, the other was to make them see how limited they would feel by the constraints of the previous part(s).

Having them experience such constraints, incorporating the stream of consciousness technique was suggested to free them from any limitations. As this technique suggested, they could put their thoughts occurring right after reading the previous part(s) or crossing their mind while reading these parts without trying to be logical, coherent or accurate. It was assumed that by freeing the participants from any kind of limitation they would be encouraged to produce more creative work. Then, they wrote a collaborative short story adopting the stream of consciousness technique. When they got stuck or needed help, I was there to help. Neither the paragraphs they wrote to practise the stream of consciousness technique nor the collaborative short story they wrote adopting the stream of consciousness technique was marked. After this intervention period ended in week 
14, the participants were asked to write a collaborative short story, getting into groups of four using the stream of consciousness technique. In total there were three groups with four people in two groups and three people in one group. Three short stories which were written in week 15 were marked by the same external examiners who marked the pre-test. Thus, the marks given to the last short stories were considered to be the post-test. The results of these pre and post-tests consisted of the quantitative data. Then, another textual data came from the post-intervention interviews which were conducted during the last week of the term. The postintervention interviews were designed to elicit information about how the stream of consciousness technique and collaborative writing affected their feelings and writing skills. Both the pre-intervention and post-intervention interviews were transcribed to be analysed qualitatively. The emerging ideas were coded and classified under relevant themes.

\section{Marking}

Drawn from the literature, assessment criteria were developed to ensure validity or reliability concerning the marking process and to help the external examiners. Research showed that criteria aided evaluators in terms of the purposes of high internal consistency as well as contributed to the quality of assessment in writing (Jonsson \& Svingby, 2007). The external examiners were recruited from the ELT department. All examiners were experienced in teaching writing. The same external examiners marked both the pre and post-tests. Before they were asked to mark the papers, they were briefed on the marking criteria, which lasted thirty minutes. In order to ensure reliability some terminology used in the criteria was clarified. Flat writing was defined as a kind of writing that included generalisations and judgements. Originality was defined as freshness or novelty, as an idea, method or performance. Likewise, invention was explained to be a unique discovery or creation and sophisticated was defined as pleasing or satisfactory to the tastes of the sophisticates or people who were educated. All examiners were given a copy of the criteria and the list of the above terms with their definitions. A grade breakdown was prepared in terms of creativity expression and overall performance ranging from 0-100. Standardization sessions were held by the examiners after the marking of both the pre-test and the post-test. These standardization sessions lasted approximately 40 to 60 minutes.

The assessment criteria were used to assess the individual short stories which were the pre-test and the collaborative short stories which constituted the post-test of the study in terms of creativity and overall performance. In the preparation of the 
criteria rather than holistic criteria, analytic criteria were preferred because such criteria assess various aspects of writing (Weigle, 2002). Furthermore, in terms of the assessment of creativity, recent research emphasized the importance of analytic criteria (Jonsson \& Svingby, 2007; Shaplin \& Morris, 2013). Last but not least, Shaplin and Morris, (2013) acknowledged analytic criteria as a reliable instrument for assessing creativity in writing.

\section{Post-intervention interviews}

The post-intervention interviews were conducted after the intervention during the last week of the term. Having undergone an intervention period in which the participants studied and practised the stream of consciousness technique along with the collaborative writing, the participants responded to the semi-structured questions about how their writing skills were affected as a result of this intervention period. The post-intervention interview questions were as follows:

1. How did you find writing with the stream of consciousness technique?

2. Were you always pleased with what you had written?

3. Do you prefer traditional short story writing or writing with the stream of consciousness technique? Why?

4. How did you find collaborative writing?

5. Do you prefer individual or collaborative short story writing? Why?

6. Do you prefer individual or collaborative written assignments? Why?

7. Have you felt completely free or did you have any kind of restrictions? If so, how?

8. Was originality important to you?

9. Have you tried to be creative?

10. How did you feel when using the stream of consciousness technique?

11. Have you ever experienced any negative feelings? If so what kind of feelings?

The post-intervention interviews were also conducted in my office. Each interview lasted about 15-25 minutes and was recorded upon each participants' verbal consent. 


\section{Composition of the groups}

It was aimed to form the groups consisting of diverse participants. In order to reach this goal, it was ensured that each group had a diversity of students according to their gender and the level of their English and that there was at least one participant in each team who exerted leadership qualities in the previous weeks. These participants were identified as Faith, Aisha and Ken. Since leadership could be critical in the success of the group (Mayne, 2012). As argued by Hernandez (2002), placing the students in heterogeneous teams ensures the diversity which would in turn helped students learn to cooperate with others. In terms of the size of each group, the literature on the relevant literature suggested a group size of four to six participants (Mahoney, 2010). This size ensured students' interaction with one another and the group being manageable.

\section{Pre and Post-tests}

Pre-test. The initial quantitative data were collected through the pre-test. Before the participants underwent the intervention period, they had been asked to write a short story individually. Having been marked by the external examiners, these short stories were considered the pre-test. In total, 11 short stories were written and marked. The aim was to assess each participants' writing skills before the intervention, which were to be compared quantitatively with the results of the posttest to see the impact of intervention on the writing skills of the participants. It was assumed that the second research question regarding how the stream of consciousness technique help undergraduate students to improve their creative writing skills would be answered through this quantitative analysis.

Post-test. After the intervention period, the participants wrote short stories in groups. There were three groups of participants. In two groups there were four participants and in one group there were three. Thus, three stories were written collaboratively and marked by the same external examiners.

The collaborative short story writing took three consecutive hours with two breaks every 50 minutes. Each student was given a pen of a different colour and a randomly chosen student in each group started the story. Then, each student reading the previous part(s) contributed to the short story with a different coloured pen. I noted down the colour of the pen each student used. By this way, I knew who contributed which part, which enabled me to track each participant's progress. 


\section{Reliability and Validity}

Reliability. It was noted that marking criteria were developed for the external examiners to rate creativity and overall writing performance when marking the pre and post-tests. Preparing the grading criteria was the first step to ensure inter-rater reliability. McHugh (2012) defined interrater reliability as 'measurement of the extent to which data collectors (raters) assign the same score to the same variable.' In addition to adhering to the same criteria, the examiners were given concise instructions as to how to spot flat writing, originality, invention and sophistication. These instructions strengthened the interrater reliability, too. The importance of the interrater reliability was apparent in that the collected data were correct representations of the variable(s) to be measured (McHugh, 2012).

Eliminating inconsistency was one of major issues in this research study since the examiners could interpret the short stories differently, which would make the results inconsistent. This was overcome by preparing the criteria and implementing briefing for these external examiners to minimize the amount of variability in the marks they gave to the pre and post-tests. For this purpose, standardization sessions were held among the examiners for both the pre and post-test results. In these sessions the examiners reviewed their marks, read the stories again and again and discussed until they all agreed on a specific mark they gave out for the stories. These standardization sessions lasted approximately 40 to 60 minutes. Being the class lecturer, I also marked the pre and post-tests according to the criteria I developed. Table 2 displays the marks given out by the external examiners and by the researchers after the standardization sessions. However, my marks were not included in the analysis but in testing reliability only to avoid any kind of bias.

Table 2

Assessment Results

\begin{tabular}{lcccc}
\hline Participants & E PreT & EPT & L PreT & L PT \\
\hline Dennis & 40 & 65 & 39 & 65 \\
Sally & 55 & 75 & 45 & 73 \\
Gina & 48 & 85 & 51 & 81 \\
Tom & 68 & 85 & 62 & 81 \\
Bradley & 35 & 75 & 45 & 75 \\
Albert & 45 & 65 & 40 & 70 \\
Aisha & 89 & 85 & 85 & 91 \\
Mina & 60 & 65 & 60 & 70 \\
Jenny & 57 & 75 & 52 & 75 \\
Ken & 75 & 85 & 75 & 86 \\
Faith & 89 & 75 & 82 & 73 \\
\hline
\end{tabular}

Key: E: External Examiner L: Class Lecturer (Researcher) PreT: Pretest PT: Post-test 
The marks given out by the external examiners were compared with those given by me to see if they correlated or not. First of all, the marks given to the pre-test by the external examiners were compared to those I gave to the pre-test. The Spearman rank order correlation coefficient between the two sets of marks was $0.94, p<0.01$. Accordingly, the external examiners' marks given to the post-test were compared to my marks for the post-test to find the correlation coefficient $0.95, \mathrm{p}<0.01$. This ensured the reliability of the criteria since as argued by Brown, Glasswell and Harland (2004), a reliability index of 0.70 was good enough to verify the reliability of any developed criteria.

Validity. Validity refers to the extent which a criterion measures what it is meant to measure (Mackey \& Gas, 2005). Face validity is simply whether the test or the criteria appears (at face value) to measure what it claims to. In order to ensure face validity, two experts examined the criteria, and both stated that the criteria were good enough to measure overall writing performance.

\section{Ethical Issues}

The ethical guidelines offered by the council of the British Educational Research Association (BERA) (2011) were followed in conducting the current research study. In terms of responsibilities to participants, each individual was treated 'fairly, sensitively, with dignity and within an ethic of respect and freedom from prejudice regardless of age, gender, sexuality, race, ethnicity, class, nationality, cultural identity, partnership status, faith, disability, political belief or any other significant difference'(BERA, 2011). This was especially important since the participants of this research were from different cultural backgrounds and they were not the same age or gender.

In line with the ethic of respect (BERA, 2011), voluntary informed consent (see Appendix B) was taken from all participants before the research study began. All participants were informed that their participation and interactions were to be analysed for research purposes only.

As regards the right to withdraw, every participant was assured that they could withdraw from the research for any or no reason at any time. Although it was designed as a course and writing the short stories was a course requirement, the participants were told that they had the right to withdraw from the research and that in case of withdrawal they would write essays instead of short stories. By this was, it was ensured that the participants who wished to withdraw would not suffer but they would be given an option. 
In terms of privacy, adhering to the norm for the conduct of research (BERA, 2011), all the participants' identities were kept confidential and anonymous. To ensure anonymity, all the participants took place in this study with pseudonyms.

\section{Pilot Studies}

In order to test the research instruments which were the pre-intervention and postintervention interviews as well as the criteria to mark the pre and post-tests the pilot studies were needed. The study was piloted for the first time with 21 fresher and sophomore participants studying at ELT, English Language and Literature and Translation and Interpretation Departments in May 2016. After the initial interviews were carried out with the participants, each of them was asked to write a short story individually in class. Then I collected these stories and gave them to the two external examiners. Having been informed about the criteria and the terminology in it, these external examiners marked them. Standardization sessions followed this marking process.

After this short story writing experience, the participating students underwent an intervention period which lasted three weeks. Three hours were allocated to teaching the stream of consciousness technique and practice of creative collaborative writing each week. Nine hours were spent in total for the intervention. At the end of this period, the participants formed groups of four with one group consisting of five students so there were five groups. Each student was given a different coloured pen in each group to make sure who wrote which part. I had five stories to be given to the examiners. Then the examiners marked them followed by standardization sessions again. The Wilcoxon signed ranks test was performed to find a significant difference between the results of the pre and posttests. This difference between the two sets of results suggested that in terms of creativity the participants improved their writing skills in general along with their creative collaborative writing skills. Then the post-intervention interviews were held with them. Thematic analysis was conducted to identify the codes and the data were classified under certain themes, which are creative effort (invention), characterization, originality, use of English and sophistication. The qualitative analysis also suggested an improvement backing up the quantitative findings. Then each student's progress was tracked in the parts they contributed to the stories written collaboratively and analysed descriptively to find traces of creativity, which suggested that the participating students improved their writing skills and creative collaborative writing skills after they were introduced to the stream of consciousness technique along with collaborative writing. The study was piloted 
for the second time with 8 junior ELL students and with ten 12th grade GCSE Arts students to find similar findings.

\section{Data Analysis}

Qualitative data analysis. The data gathered from the initial interviews and the post-intervention interviews were analysed qualitatively. Qualitative inquiry delves into 'participants' perspectives, their meanings and their subjective ways' (Creswell, 2007, p. 38). Qualitative data analysis requires the analysis of the data 'inductively, recursively and interactively' (Creswell, 2007, p. 38). The data obtained from the interviews were organized 'into increasingly more abstract units of information' which helped me 'build the patterns, categories and themes from the bottom up' (Creswell, 2007, p. 38).

One of the strengths of qualitative inquiry is that it conveys participants' meanings. In the whole qualitative inquiry process the main focus was on 'learning the meaning that the participants hold about the issue (Creswell, 2007, p. 38). For this reason, qualitative data analysis served well to answer the research questions about the perspectives of the participants on the effect of the stream of consciousness technique on their creative collaborative writing skills by generating answers to this research question. The qualitative analysis of the pre-intervention interviews revealed the participants' perspectives on their own writing skills, difficulties they experienced when writing, and how they felt while writing. Qualitative analysis of the pre and post-intervention interviews provided deeper insights into the participants' perspectives in this respect. In addition, as Cohen, Manion and Morrison (2007) put, qualitative analysis especially works well with small number of participants.

Creswell (2007) noted that the core elements of qualitative data analysis consisted of coding, integrating the codes into broader themes and displaying in the tables. Creswell (2007) himself preferred 'lean coding' which meant drawing five or six categories with 'shorthand labels or codes' and expanding the categories when reviewing the database. Following on Creswell (2007) 'lean coding' was adopted rather than developing long and detailed lists of codes. Figure 2 displays some sample themes along with the codes that came out at the initial stage of the data analysis.

The textual data gathered from the post-intervention interviews were also analysed adopting and following the same procedures as those performed for the preintervention interviews. Further, the qualitative outcomes elicited from the pre and 
post-intervention interviews were compared qualitatively for each participant to display the extent they benefited from the intervention and see if their perspectives towards writing and their own writing performance were changed or not.
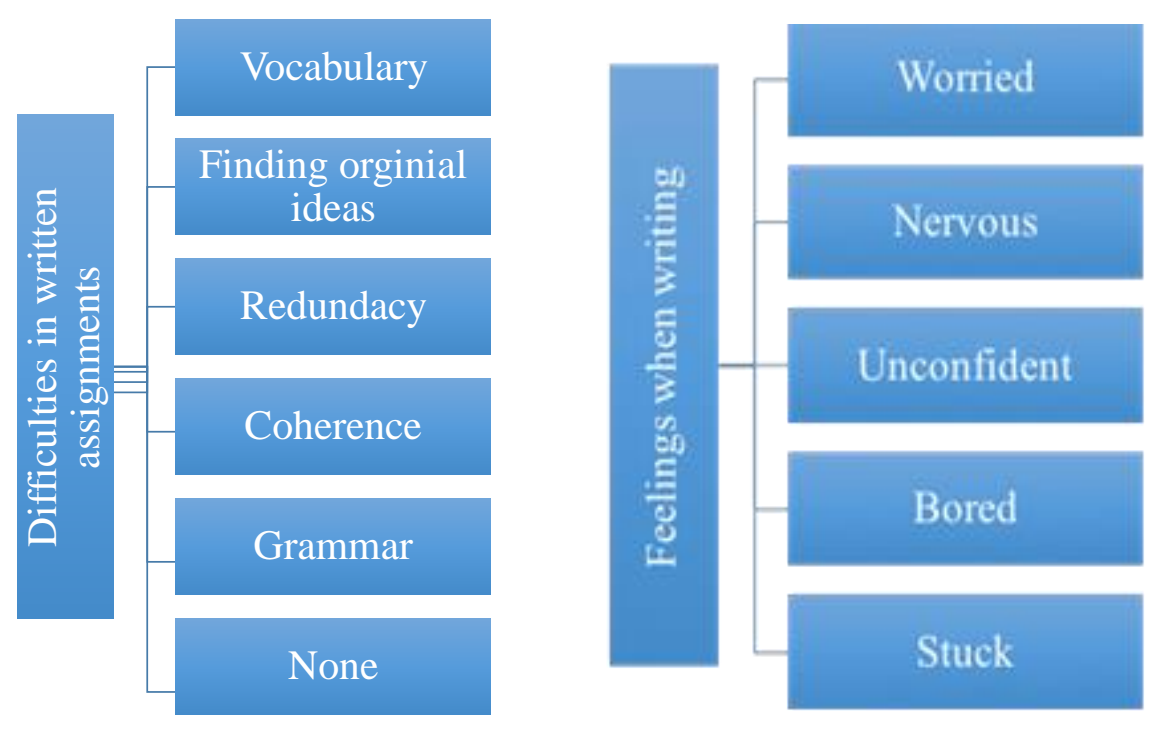

Figure 2. Sample themes

Quantitative data analysis. The results of the pre-test were compared with those of the post-test quantitatively. As put by Pratt, Mc Guigan and Katzev (2000) in pretest -post-test model a pre-test was administered to the participants prior to the intervention to measure the variable(s) to be tested. Then, the participants went through an intervention program at the end of which a post-test was given. The effects of the intervention were determined based on the differences between the two measures, namely the pre-test and post-test (Pratt et al., 2000). By this pre-testpost-test design, it was assumed that the change in the participants' writing skills and creativity measures could be determined. Because this model provided a measure of participant skills prior to the intervention, it was helpful in focusing on the change taking place at the end of the intervention period.

Although quantitative methods are used for large scale studies, they also work well with small scale research (Cohen et al., 2007). This research study was a small scale study conducted with a small group of participants and the distribution of the outcome variable was not normal. The Wilcoxon signed ranks test was performed to compare the pre and post-tests. The Wilcoxon signed ranks test was a nonparametric test for paired or matched data, such as the results of pre- and posttreatment measurements based on independent units of analysis (Rosner, Glynn \& 
Lee, 2006). For this reason, the Wilcoxon signed ranks test was performed for this research study to observe whether there was a statistically significant difference in the outcome variable between the pre and post-tests with a non- normally distributed outcome variable.

The individual short stories that were written by the participants before the intervention process were marked by five external examiners according to the criteria developed by me. These stories were considered the pre-test. Employing the same criteria, these examiners marked the short stories written collaboratively adopting the stream of consciousness technique after the invention period. These short stories constituted the post-test. There were 11 short stories written individually and there were 3 short stories written collaboratively. The marks of these pre and post-tests were compared quantitatively to evaluate the efficiency of the intervention.

\section{Findings}

The Wilcoxon signed ranks test displayed a significant difference between the results of the pre and post-tests, $z=2.49, \mathrm{p}<.05$. When the mean rank and the sum of ranks were considered, the significant difference was found in favour of the positive ranks which were the post-test results. Based on the higher mean rank of the post-test, it was suggested that the participants scored better in the post-test than they did in the pre-test, which proved that the intervention improved creativity and overall writing performance of the participants considerably.

\section{Table 3}

Wilcoxon Signed Ranks Test Results for Pre and Post-tests

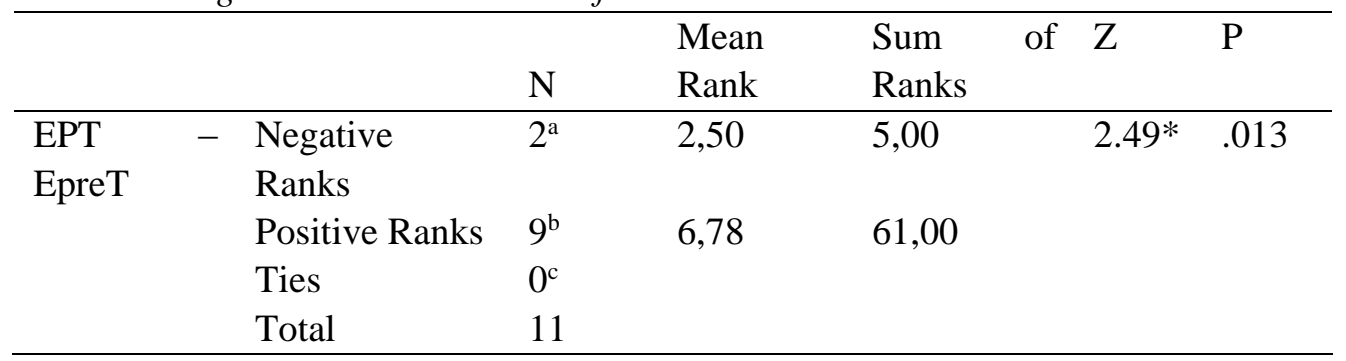

a. Based on negative ranks.

b. Wilcoxon Signed Ranks Test

In general, it was determined that exposure to the stream of consciousness technique and collaborative writing enhanced the undergraduate students' 
performances in terms of creativity and overall writing performance. When the results of the pre and post-test results were considered, it was noticed that except for two participants (Aisha and Faith) all participants made good progress with their writing performances (see Table 2).

\section{Perspectives on the Stream of Consciousness Technique}

Being a recommended new approach to writing (Cowly, 2011), the stream of consciousness technique in writing was a technique which enabled learners to relinquish formal control which restricted learners by preventing them from expressing themselves freely. When learners moved away certain restrictions like ensuring mechanical accuracy, logical organisation and using suitable vocabulary in EFL writing, learners were expected to be more creative since their focus would be the content rather than the form and rules of composing. This shift from linguistic concerns and composing rules to content was expected to make way to richer content with creative ideas.

The stream of consciousness technique was introduced to the participants during the intervention period and the participants had the opportunity to practise this technique. Their views concerning this technique were extracted from the data elicited through the post-intervention interviews and presented in Table 4.

\section{Table 4}

Students' Perspectives on the Stream of Consciousness Technique

Positive Themes Negative Themes

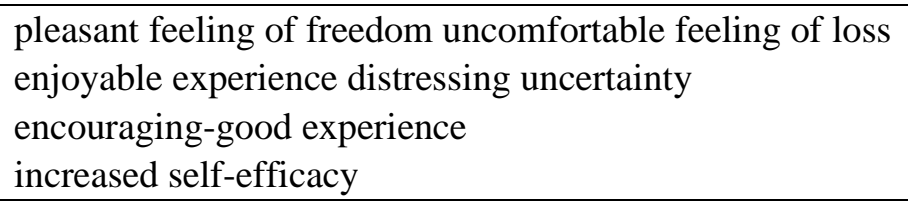

As Table 4 illustrated the positive themes elicited from the post-intervention interviews outnumbered the negative ones. In relation to the positive comments, four themes emerged which were pleasant feeling of freedom, enjoyable experience, encouraging experience and increased self-efficacy. Along with the positive comments, there were also few negative comments. Two themes emerged concerning the negative comments which were the uncomfortable feeling of loss and distressing uncertainty. 


\section{Perspectives on Collaborative Writing}

Due to the collaborative nature, collaborative writing encompassed working together on a written task and sharing the responsibility of the written work. For this reason, it was quite different from individual writing. While students had to take all the responsibility in individual writing, they shared the responsibility in collaborative writing. Similarly, while students were under pressure in individual writing, they experienced less pressure as a result of the opportunity to share the written work and support one another in collaborative writing. Collaborative writing was especially effective in EFL writing. As asserted by Graham (2005), through collaborative writing in EFL learners could generate ideas together. Besides, collaborative writing in EFL classes encouraged students to act socially and cognitively by promoting interaction and the co-construction of knowledge (Storch, 2002).

The participants were already familiar with individual writing; however, they had not experienced collaborative writing. Collaborative writing was introduced to them during the intervention period and their perceptions of this technique were elicited through the data gathered from the post-intervention interviews. Table 5 displayed the findings concerning the perceptions of the participants of collaborative writing.

\section{Table 5}

Students' Perspectives on Collaborative Writing

\begin{tabular}{ll}
\hline Positive Themes & Negative Themes \\
\hline engaging cooperation & distressing uneven contribution \\
pleasing experience & \\
enhanced encouragement & \\
increased self-efficacy & \\
facilitated cognition & \\
\hline
\end{tabular}

When the post-intervention interview data were analysed, five themes emerged in terms of the positive perceptions of collaborative writing, which were engaging cooperation, pleasing experience, enhanced encouragement, increased self-efficacy and facilitated cognition. Despite the fact that there were more positive comments, not all of them were positive. Two participants complained that some group members did not contribute adequately. 


\section{Discussion and Conclusion}

The intervention in which collaborative writing and the stream of consciousness technique integrated improved the participants' creativity and overall writing performances. Integrating these two approaches to writing contributed to a new, interesting and encouraging learning experience for the participants who took part in the writing course designed for the purposes of this study.

Before the intervention, the participants wrote individual short stories to be marked by the external examiners as the pre-test. After the intervention, they were asked to write a short story adopting collaborative writing and the stream of consciousness technique in groups. These short stories were marked by the external examiners as the post-test. The results of these pre and post-test results were compared through the Wilcoxon signed ranks test which displayed a significant difference between the results of the pre and post-tests. The significant difference was found in favour of the positive ranks which were the post-test results. Based on the higher mean rank of the post-test, it was found that the participants scored better in the post-test than they did in the pre-test, which proved that the intervention improved creativity and overall writing performance of the participants considerably. Bearing in mind that the intervention lasted 16 weeks only, it was suggested that this progress did not take a very long time. It was argued that choosing appropriate approaches like collaborative writing and the stream of consciousness technique and incorporating them into writing classes, it was possible to empower undergraduate students with creativity and better writing skills.

The possible reasons for this progress was due the advantages of collaborative writing and the stream of consciousness technique which were identified by the participants. However, another reason drawn from the literature could be the fact that reading on the relevant issue fostered writing (Krashen, 2003). During the intervention period the participants were required to read extracts from Mrs. Dalloway, Ulysses, A Room of One's Own, The Story of an Hour, Leutnamt Gustl to exemplify the stream of consciousness technique and various articles on collaborative writing.

Another finding suggested that most participants found their writing performances during individual writing dissatisfying. It was an expected finding since they had not received effective writing instruction. Besides, they were not introduced to new techniques. Due to the cooperation, pleasure, encouragement, self-efficacy and cognition, which collaborative writing provided, the participants had the opportunity to share the responsibility, had fun, shared the responsibility, felt encouraged and learnt from each other. Similarly, the feeling of freedom, pleasure, 
encouragement and self-efficacy triggered by the stream of consciousness technique lowered anxiety and enabled the participants' focus to change from form to content. This in turn fostered creativity and overall writing performance. As a matter of fact, a great majority of the participants preferred collaborative writing over individual writing and all participants preferred the stream of consciousness technique over the traditional writing modes.

Another finding was that the stream of consciousness technique was highly valued in terms of fostering creativity and overall writing skills. As voiced by seven participants, the main reason for this was found to be the feeling of freedom the stream of consciousness technique offered. Once freed from any kind of limitations, such as grammatical accuracy and organisational rules, the participants had a convenient atmosphere to be less worried and more creative. It was quite important that most participants told that they were worried, uneasy and uncomfortable during writing before the intervention. It might not be possible to help students overcome their worries and anxiety in traditional ways of teaching writing. Bearing this in mind, the stream of consciousness technique was employed so that the participants would feel free, enjoy themselves and be imaginative. It was found that the stream of consciousness technique helped the participants to have positive feelings towards writing.

Both the qualitative and the quantitative findings suggested that due to the intervention they not only made good progress in terms of their writing skills but also their attitudes changed in a positive way towards writing. For this reason, it could be posed that reading literature illustrating the stream of consciousness technique fostered positive feelings towards writing in a short period. Thus, the stream of consciousness technique revealed the importance of literature and reading in improving writing skills. In this respect, the stream of consciousness technique linked English language education and literature.

It was found that the participants had some supportive experiences. The postintervention interview data revealed that the participants felt supported in terms of writing. This attitude might have developed by the encouraging, unlimited, creative and cooperative treatments during the intervention. The possible reason for this change could be that when the participants were introduced to prominent novelists like Virginia Woolf, they had one on one experience with the technique and read examples of creativity and imagination. Seeing these examples and discussing the advantages of this technique might have motivated and encouraged the participants to be more creative and imaginative. In considering the participants' perspectives on the stream of consciousness technique, it was possible to state that the participants got rid of the boredom, anxiety and dissatisfaction they had in 
traditional writing modes and this riddance in turn enhanced their motivation towards writing.

A great majority of the participants preferred collaborative writing over individual writing. This finding was an expected finding when the advantages of collaborative writing were taken into account. A possible reason for this preference could be the fact that the participants did not take the whole responsibility of the written work as in individual writing but shared it with other group members. Sharing the responsibility is one of the advantages of collaborative writing (Storch, 2002). When the participants shared the responsibility, it decreased the pressure they felt during the individual writing, which made them less worried and hence more motivated.

When the participants were given the opportunity to prefer individual or collaborative writing, they chose collaborative writing. This finding was in line with Storch's (2005) finding. The possible reasons for this preference in favour of collaborative writing could be the pleasure they got (Louth, McAllister \& McAllister, 2010) and less responsibility they felt during collaborative writing. Since the participants had fun, they were more motivated (Phipps, Phipps, Kask \& Higgins, 2001), and this was reflected in their writing performances. As they had fun and felt less responsibility, they used their imagination and wrote more creatively.

Another finding concerning collaborative writing was that collaborative writing built self-esteem. The participants felt more confident during collaborative writing than they did in individual writing (Gabriele, 2007). The reason for their enhanced self-efficacy was due to the cooperation between the group members. Whenever they were stuck and needed help, the group members were ready to help.

It was found that collaborative writing was valuable in encouraging the participants who had poor writing skills. The reason for this could be the fact that cooperation between the group members fostered the self-efficacy of the participants who had poor writing skills.

Another finding was that even the participants who were low motivated felt encouraged by collaborative writing. Hill \& Hill (1990) found that collaborative writing encouraged low- motivated students to participate.

Cognitive development was enhanced through collaborative writing. The reason for this was that the students who had poor writing skills co-constructed knowledge with the students who had better writing skills. Thus, they had the opportunity to increase their own knowledge. Cognitive development was fostered in 
collaborative dialogue with other (more-skilled) peers (Mirzaei \& Eslami, 2013; Dobao, 2012). Students' co-construction of knowledge when participating in collaborative dialogue enhanced creativity by eliminating psychological barriers (Wass, Harland \& Mercer, 2010). The participants of this current study revealed that they learnt from each other during collaborative writing. Kostouli (2009) argued that along with texts meanings are constructed together in collaborative writing. Group members shared ideas as to what could or could not be involved due to the social nature of collaborative writing (Lowry, Curtis, \& Lowry, 2004; McAllister, 2005).

It was also found that students with good writing skills complained about the performance of some peers who were not as good as them at writing. As described one of the disadvantages of collaborative writing in the relevant literature (Gupta, 2004; Maiden \& Perry, 2011), students' greatest complaint about collaborative writing was that some students' contribution was less than other group members. The possible reason for this complaint was that the students who were good at writing believed that the ones with poor writing skills would rely on them, would not contribute much but still got a good mark due to the efforts of the good ones.

In terms of the use of the use of the stream of consciousness technique and collaborative writing, it was found that collaborative writing was a more pleasing experience. The participants felt under pressure during individual writing but found the collaborative writing a pleasing experience. The prospective English teachers made a considerable progress in terms of the quality of the written texts owing to the atmosphere collaborative writing and the stream of consciousness technique provided.

Although few, there were also some negative comments on collaborative writing and the stream of consciousness technique. The collaborative writing was criticised for uneven contribution. Especially the participants with good writing skills complained about that some students relied on the good ones and did not do their best. This might create problems in the marking process, however, when each group member's performance was marked separately, this problem could be solved. With regard to the stream of consciousness technique, there were complaints about the feeling of loss and uncertainty. The reasons for these negative comments were due to the fact that these participants practised traditional ways of writing for several years. Since they were not familiar with these new techniques, they might have adaptation problems. It was an expected finding when it was considered that the participants were used to the traditional ways of writing and felt lost when they adopted a new technique which provided them with freedom offering a creative atmosphere. Despite this, the fact that a great majority of the 
participants presented positive perceptions suggested that the stream of consciousness technique was effective in fostering creativity and overall writing skills.

\section{Recommendations}

In order to raise motivation and self-efficacy, collaborative writing and the stream of consciousness technique should be implemented into writing classes by teachers and students must be open to these new techniques since they are found to be effective in this study. Following on research findings, curriculum developers should integrate collaborative writing and the stream of consciousness technique into writing curriculum. They should also organise workshops for teachers informing and encouraging them to use such techniques.

\section{References}

Abdulrahman, B., (2012). Effects and implications of pragmatic competence in enhancing EFL university students' written performance. Author House UK: Milton Keynes.

Belanger, J. (2001). A Portrait of the artist as a young man. London: Wordsworth.

British Educational Research Association-BERA, (2011). Ethical guidelines for educational research. Retrieved from https://www.bera.ac.uk/researchers-resources/

publications/ethical-guidelines-for-educational-research-2011. [Accessed 10 ${ }^{\text {th }}$ July 2017]

Brown, G.T. L., Glasswell, K. \& Harland, D. (2004). Accuracy in the scoring of writing: Studies of reliability and validity using a New Zealand writing assessment system. Assessing Writing, 9 (2), 105-121. Available from https: //doi.org/10.1016/j.asw.2004.07.00

Cohen, L., Manion, L. \&Morrison, K. (2007). Research methods in education (6th ed.). New York, NY: Routledge.

Creswell, J. (2007). Qualitative inquiry and research design: Choosing among the approaches (2nd ed.). Thousand Oaks, CA: Sage.

Dainton, B. (2000). Stream of consciousness: Unity and continuity in conscious experience. London: Routledge.

Dobao, A. F. (2012). Collaborative writing tasks in the L2 classroom: Comparing group, pair, and individual work. Journal of Second Language Writing, 21, 40-58. Available from: https://doi.org/10.1016/j.jslw.2011.12.002

Freud, S. Wilson, S. (2012). A general introduction to psychoanalysis. London: Wordsworth.

Gabriele, A. J. (2007). The influence of achievement goals on the constructive activity of low achievers during collaborative problem solving. British Journal of Educational Psychology, 77 (1), 121-141. Available from doi: 10.1348/000709905X89490

Gay, L. R. \& Pirasian, P. (2000). Educational research: Competencies for analysis and application (6th. ed.). Upper Saddle River, New Jersey: Merrill Publishing Company.

Graham, D. (2005). Cooperative learning methods and middle school students (Doctoral Dissertation, Capella University) Retrieved from https://scholar.google.com/ scholar? 
$\mathrm{q}=+$ cooperative+learning + methods + graham $+2005 \& \mathrm{btnG}=\& \mathrm{hl}=\mathrm{en} \& \mathrm{as} \_\mathrm{sdt}=0 \% 2 \mathrm{C} 5 \& \mathrm{a}$ _vis=1

Gupta, M. (2004). Enhancing student performance through cooperative learning in physical sciences. Assessment \& Evaluation in Higher Education, 29 (1), 63-73. Available from_http://dx.doi.org/10.1080/0260293032000158162

Hedgcock, J. \& Lefkowitz, N. (1992). Collaborative oral/aural revision in foreign language writing instruction. Journal of Second Language Writing, 1, 255-276. Available from https://doi.org/10.1016/1060-3743(92)90006-B

Hernandez, S. A. (2002). Team-based learning in a marketing principles course: Cooperative structures that facilitate active learning and higher level thinking. Journal of Marketing Education, 24 (1) 45-75. Available from https://doi.org/10.1177/ 0273475302241009

Hill, S. \& Hill, T. (1990). The collaborative classroom: a guide to cooperative learning. South Yarra: Eleanor Curtain.

Honigsfeld, A.\& Dove, M., (2012). Co-teaching and other collaborative practices. Charlotte: Information Age Publishing.

James, W. (1890). The principles of psychology. Harvard: Harvard University Press.

Johnson, R., Onwuegbuzie, A. \& Turner, L. (2007). Toward a definition of mixed methods research. Journal of Mixed Methods Research, 1 (2), 112-133. https://doi.org/ $10.1177 / 1558689806298224$

Jolliffe, W. (2007). Cooperative learning in the classroom. London: Paul Chapman Publishing.

Jonsson, A. \& Svingby, G. (2007). The use of scoring rubrics: Reliability, validity and educational consequences. Educational Research Review, 2, 130-144. Available from https:// doi.org/10.1016/j.edurev. 2007.05.002

Joyce, J. (1922). Ulysses. Paris: Sylvia Beach.

Kostouli, T. (2009). A sociocultural framework: writing as social practice. In R. Beard, D. Myhill, J. Riley, \& M. Nystrand (Eds.), The SAGE handbook of writing development. London: Sage Publications Ltd. Available from doi:10.4135/9780857021069.n7

Krashen, S. (2003). Exploration in language acquisition and use. Portsmouth: Heinemann.

Lowry, P. B., Curtis, A., \& Lowry, M. R. (2004). Building a taxonomy and nomenclature of collaborative writing to improve interdisciplinary research and practice. Journal of Business Communication, 41(1), 66 -99. Available from doi:10.1177/00219 43603259363

Mackey, A. \& Gas, S. (2005). Second language research. New Jersey: Lawrence Erlbaum Associates.

Mahoney, K. (2010). Team-Based Learning. In an introduction to medical teaching. W. Jefferies and K. Huggett (Eds.), 55-64. Dordrecht: Springer.

Maiden, B. \& Perry, B. (2011). Dealing with free-riders in assessed group work: Results from a study at a UK University. Assessment \& Evaluation in Higher Education. 36 (4), 451-464. Available from doi: 10.1016/j.edurev.2007.05.002

Mayne, L. (2012). Reflective writing as a tool for assessing teamwork in bioscience. Biochemistry and Molecular Biology Review, 49 (4), 234-249. Available from doi:10.1002/bmb.20621

McHugh, M. L. (2012). Interrater reliability: The Kappa statistic. Biochemia Medica, 22 (3), 276-282.

Mirzaei, A. \& Eslami, Z. R. (2013). ZPD-activated languaging and collaborative L2 writing. Educational Psychology: An International Journal of Experimental 
Educational Psychology, $35 \quad$ (1), 5-25. Available from http://dx.doi.org/10.1080/01443410. 2013.814198

Myles, J. (2002). Second language writing and research: The writing process and error analysis in student texts. TESL-EJ, 6(2). Available from http://wwwwriting.berkeley.edu/TESL-EJ/ej22/toc.html

Nation, I. (2009). Teaching ESL/EFL reading and writing. New York: Routledge.

Phipps, M., Phipps, C. Kask, S. \& Higgins, S. (2001). University students' perceptions of cooperative learning: Implications for administrators and instructors. Journal of Experiential Education, 24 (1),14-21. Available from https://doi.org/10.1177/ 105382590102400105

Pineteh, E. A. (2013). The academic writing challenges of undergraduate students: A South African case study. International Journal of Higher Education, 3(1), 12-22. Available from doi:10.5430/ ijhe.v3n1p12.

Pratt, C. C., McGuigan, W.M.\& Katsev, A. R. (2000). Measuring program outcomes: Using retrospective surveys to obtain complete data sets and measure impact in extension programs. American Journal of Evaluation, 21(3), 341-349.

Rosner, B., Glynn, R. J. \& Lee M-L. T. (2006). The Wilcoxon signed rank test for paired comparisons of clustered data. Biometrics, 62, 185-192. Available from doi:10.1111/j.1541-0420.2005.00389.x

Shaplin, E. \& Morris, G. (2013). The assessment of creative writing in senior secondary English: A colloquy concerning criteria. English in Education, 47, 49-65. Available from doi: 10.1111/eie.12004

Solak, E., \& Bayar, A. (2015). Current challenges in English language learning in Turkish EFL context. Participatory Educational Research (PER), 2(1), 106-115. Available from http://dx.doi.org/ 10.17275/per.15.09.2.1

Storch, N. (2002) Patterns of interaction in ESL pair work. Language Learning, 52 (1), 119-158. Available from doi: 10.1111/1467-9922.00179

Storch, N. (2005). Collaborative writing: Product, process and students' reflections. Journal of Second Language Writing, 14, 153 - 173. Available from https://doi.org/10.1016/ j.jslw.2005.05.002

Wass, R. Harland, T. \& Mercer, A. (2010). Scaffolding critical thinking in the zone of proximal development. Higher Education Research \& Development, 30, 317-328. Available from http://dx.doi.org/10.1080/07294360.2010.489237

Weigle, S. C. (2002). Assessing writing. New York: Cambridge University Press.

White, E. M. (1991). Assessing higher order thinking and communication skills in college graduates through writing. Available from http://files.eric.ed.gov/fulltext/ED340767. pdf [Accessed $9^{\text {th }}$ August 2017]

Wong, V. F. \& Lim, J. (2013). Linking communicative functions with linguistic resources in short stories: Implications of a narrative analysis for second language writing instruction, System, 45, 147-162. Available from https://doi.org/10.1016/j.system.2014.05.008

Woolf, V. (1964). Mrs. Dalloway. Australia: Penguin. 